\title{
Effect of Working Fluid on Thermal Performance of Closed Loop Pulsating Heat Pipe
}

\author{
J.Venkata Suresh, P.Bhramara, S.Sai Krishna
}

\begin{abstract}
The pulsing heat pipe (PHP) is an technology that is increasingly capable of applying many manufacturing areas, but a thorough knowledge of its thermo-hydrodynamic There's far from enough system. This research explored the features of oscillation and the heat transfer efficiency of a closed-loop PHP using an internal and external diameter copper tube with 2.0 and $3.0 \mathrm{~mm}$ respectively. For all experimentation, filling ratio $(F R)$ was $40 \%$, five turns and different heat inputs of 20 to $80 \mathrm{~W}$ was supplied to PHP. The position of the PHP was vertical bottom heat type. $52 \mathrm{~mm}, 170 \mathrm{~mm}, 60 \mathrm{~mm}$ was retained for the duration of the evaporator, adiabatic and condenser section. Water, Ethanol are chosen as working liquids. To understand, thermal resistance features and median evaporator pressures for multiple operating liquids at distinct heat inputs. An significant consideration for the results of PHPs is the research on PHP stated operating fluid. The result demonstrates that, with the rise of the heating output from 20 to $80 \mathrm{~W}$, where as steadily increases above $80 \mathrm{~W}$, the thermal resistance reduces faster. By comparing Water, Ethanol working fluids, Ethanol provides the highest heat performance. The simulation is performed in Mat lab and the results have been contrasted.
\end{abstract}

Keywords: Closed loop pulsating heat pipe (CLPHP), Artificial neural network, Thermal performance, Thermal resistance

\section{INTRODUCTION}

\subsection{Introduction}

In this generation development of electronic devices like LED chip and central Processing chips are becoming miniature and cohesive which release the Large quantity of electronic board heat flux. This heat flux from the structure can degrade the system's thermal efficiency Technology for heat pipes was the solution to the problem to dissipate the heat from device it uses phase change form and transfer Working fluid's latent heat and transport the heat from the source to sink this solves the heating problem off the device In attempt to improve heat pipe capacity and heat carrying

Revised Manuscript Received on December 30, 2019.

* Correspondence Author

J.Venkata Suresh*, Asst. prof. \& Reasearch Scholar JNTUCEH, Department of Mechanical Engineering, GRIET, Hyderabad, Telangana, India .venkatasureshj@gmail.com

Dr.P.Bhramara, professor, Department of Mechanical Engineering, JNTU College of Engineering, Hyderabad, Telangana, India bhramara74@jntuh.ac.in

S. Sai krishna, PG Student, Department of Mechanical Engineering, GRIET, Hyderabad, Telangana, India . saikrishna4685@gmail.com

(C) The Authors. Published by Blue Eyes Intelligence Engineering and Sciences Publication (BEIESP). This is an open access article under the CC BY-NC-ND license (http://creativecommons.org/licenses/by-nc-nd/4.0/) efficiency, the proper working fluid characteristics should be found.

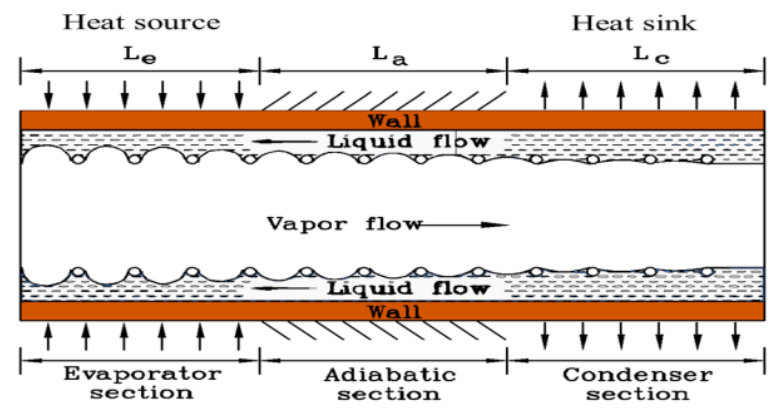

Figure: 1.1 Heat pipe

1.2 Working Principle of Heat Pipe:

The source heat is observed in the section of the evaporator (figure 1.1). The heat flux moves through the heat pipe ceiling through the wick framework where the working fluid gets heat and changes the stage. The result is that the vapors create the stress and move the vapor through adiabatic segment two of the condenser, then the phase change and release the latent heat again requires position. The heat is supplied to plunge heat. The capillary pressure generated by the menisci in the wick transfers the liquid phase to the evaporator portion. The heat pipe can therefore bring the latent heat continually from origin to plunge.

Continuous thermal transfer provided capillary stress is adequate to restore the condensate liquid to the evaporator (origin section).

\subsection{Working Principle of Pulsating heat pipe:}

Pulsating heat pipe (Fig. 1.2) are developed from long capillary tube with many turns three segments are available present in the system evaporator section, adiabatic section and condenser section. There are two types of pulsating heat pipes

1. Closed loop pulsating heat pipe

2. Open loop pulsating heat pipe

By viewing the pulsating heat pipe, we can tell whether it is an open loop pulsating heat pipe or a closed loop pulsating heat pipe that is united or not by seeing the two starts. It is filled with operating liquid by pulsating heat pipe. The operating liquid proportion ranges from $40 \%$ to $60 \%$. The pulsating heat pipe diameter is tiny. When the boiling starts, vapor plugs and liquid slugs are created in the pipe. Pulsing heat pipe is defined as it creates the evaporative cooling to transport the thermal energy from one section to another, which is why the fluid is evaporated and condensed. The pulsing heat pipe or relies on the distinction in temperature between the pipe segments. 
At both ends below the ambient temperature, it can not be small pressures. The fluid existing in the PHP at the start of the evaporator rises the pressure in the heat pipe chamber when the evaporator part is stirred.

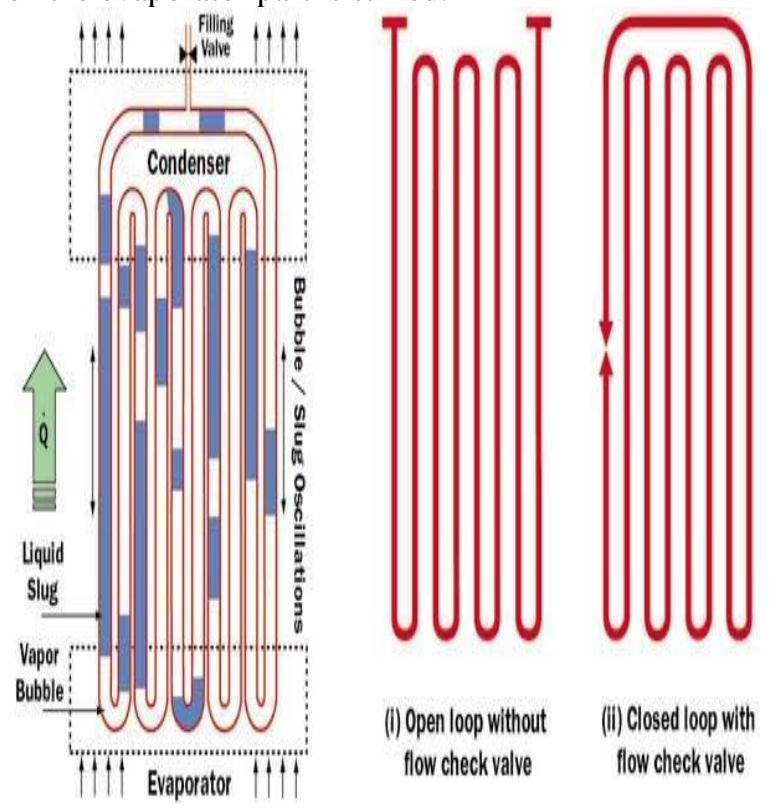

Fig.1.2 Schematic diagram of pulsating heat pipe

\section{EXPERIMENT SETUP}

The experimental set-up of CLPHP consists of an evaporator, condenser and transparent adiabatic section. There is a separate control panel for the measuring instruments, as shown in Fig. 2.1. The CLPHP is developed and tested in the laboratory, which consists of a five loop of capillary dimensions, partly made of copper (ID: $2.0 \mathrm{~mm}$, OD: $3.6 \mathrm{~mm}$ ) and partly of glass (ID: $2.0 \mathrm{~mm}$, OD: $4.0 \mathrm{~mm}$ ). The gap is sealed with a mixture of M-seal, araldite and welded. A typical method of sealing of copper and glass tube is arranged to visualize liquid slugs and liquid plugs. The lengths of evaporator, condenser and adiabatic section are chosen as 42 $\mathrm{mm}, 50 \mathrm{~mm}$ and $170 \mathrm{~mm}$, respectively. The distance between tubes was $20 \mathrm{~mm}$, and overall size of device is $60 \mathrm{~mm} \times 262$ $\mathrm{mm}$. The evaporator section is well thermally insulated by using asbestos rope, glass wool and asbestos sheet sequentially. To obtain a vacuum in the tube, a reciprocating vacuum pump was connected to the filling valve, to create vacuum level is at least lower than $70 \mathrm{~cm}$ of $\mathrm{Hg}$.

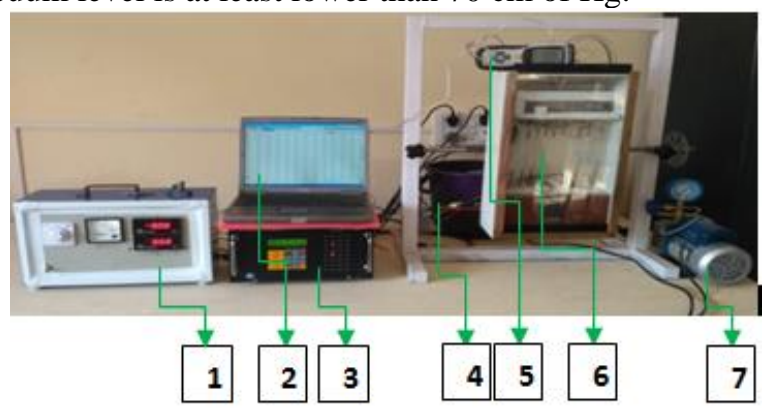

Figure 2.1 Experimental Setup of PHP

1.Heat variac 2.Data Recording laptop 3.Data logger 32 channel 4.water motor 5.Manometer 6.PHP 7.Vaccum pump

The PHP position was maintained at vertical bottom heat mode (BHM). Heat was removed in the condenser section by providing a cooling bath with water. Condenser block is made up of acrylic sheet having size 85 x 65 x $20 \mathrm{~mm}^{3}$.

Ten thermocouples (T1 T10) were symmetrically attached just above the condenser section; and ten thermocouples (T13 T22) below the evaporator section. In addition, one thermocouple each, at inlet (T11) and outlet (T11) of the condenser was used, to monitor the temperature difference. Four thermocouples (T23 T26) were symmetrically attached to walls of evaporator; and four thermocouples (T27 T30) were symmetrically attached to walls of condenser. A flow meter was used to record mass flow rate of cooling water in the condenser section. The model of the manometer was pm6105. The data logger in the experiment was 32 channel the type of inputs was RTD Pt100 (3 wire), DC Volt, DC milli ampere, and Thermocouples (J) Type of input is settable for each channel from keypad.

\section{Experimental Results: \\ 2.1 Water:}

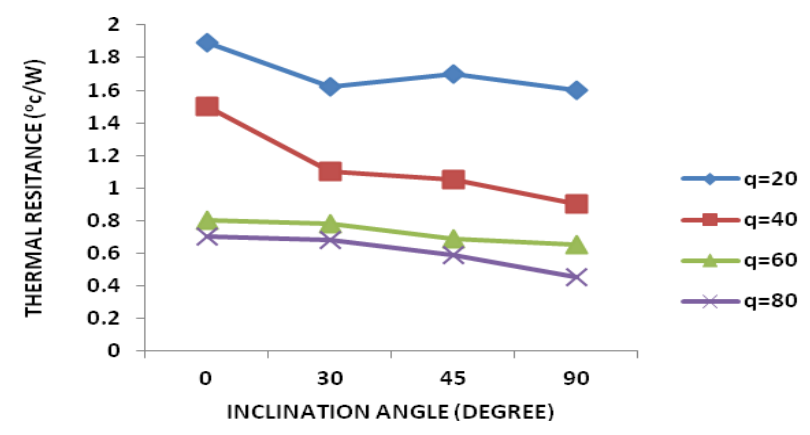

Graph 2.1 Variation of Thermal resistance Vs Inclination Angle for different heat inputs at $\mathbf{4 0 \%}$ fill ratio (Water as working fluid).

From the above graph $\mathbf{2 . 1}$ the thermal resistance of water at separate heat inputs with a fill ratio of $40 \%$ percent at distinct corners. As the heat output rises, the thermal resistance reduces at $90^{\circ}$ degrees inclination, the thermal resistance is low. Graph variety owing to thermal resistance reduces with heat output rises. As heat input rises, more fluid will be vaporized so that heat can be emitted by phase change all the more effectively. As the vaporization rate is close to the heat input measurement, the molecular connection reduces so that thermal resistance reduces.

\subsection{Ethanol :}

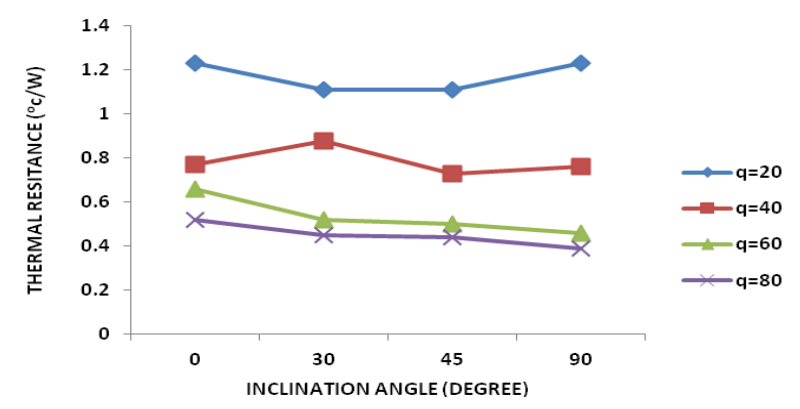

Graph 2.2 Variation of Thermal resistance Vs Inclination Angle for different heat inputs at $\mathbf{4 0 \%}$ fill ratio (Ethanol as working fluid). 
From the above graph 2.2 the thermal resistance of ethanol at separate heat entry with a mix proportion of $40 \%$ percent at distinct corners. As the heat output rises the thermal resistance declines at an inclination of $45^{\circ}$ degrees the thermal resistance is small. Graph variability owing to thermal resistance reduces with heat output rises. As heat output rises, more fluid is vaporized so that through phase change heat can be emitted even more effectively.

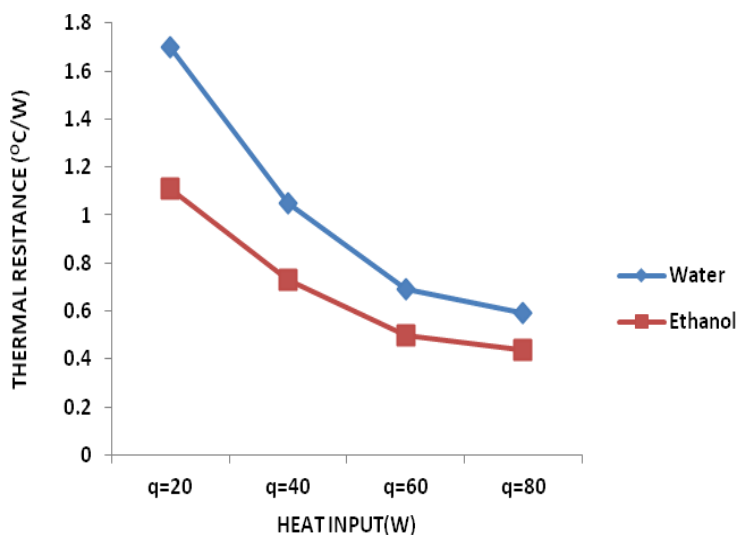

Graph 2.3 Comparison of Thermal resistance of water and ethanol at different heat input for $\mathbf{4 0 \%}$ fill ratio.

As the vaporization concentration is close to the heat output measurement, the molecular connection reduces as a result of a decrease in thermal resistance. The thermal resistance of two operating liquids is measured from the above graph 2.3 as compared to water and ethanol heat resistance is small. Because the surface tension is large at greater altitudes for the self-reinforcing liquids because of this it sticks to the heat pipe ceilings and transfers more heat. Compared to water and ethanol, ethanol gives the better results

\section{ARTIFICAL NEURAL NETWORKS}

\subsection{Introduction:}

The cellular interactive network was a mathematical model extracted from the biological networks operational and organizational. Like linear regression assessment, the cellular network uses nonlinear mathematics and can be used to fix extremely complex functions. To locate inputs and inputs, these types of networks are used. To discover trend in information it took the big laboratory information to coach the network for the issues another one is not appropriate for the physical phenomenon, conceal the dynamics of the scheme it can only offer projections in the training spectrum Network. khandekar [ 2002 ] first designs the pulsating heat pipe using the artificial neural network template. Using some information collections of pulsating heat pipe, he used feed forward learning feature to coach the network. As destination information, the heat output and finish proportion job performed as inner input resistance is drawn. Therefore, it calculates the expected thermal resistance, neglecting many parameters such as operating fluid, measuring geometry. This model shows some drawbacks after all the scientist pursued him.

\subsection{ANN Modeling Procedure:}

The following steps briefly summarize any typical ANN modelling procedure

Step: 1 Task identification and planning
1. Give the task to the network to perform in the application.

2. Data is analyzed.

3. The input data is imported as input to the network.

4. The output data is important as target data to the network

Step: 2 Developing ANN Architecture

5. Select the artificial neural network learning method to train.

6. choose the parameters in the network. Select the processing elements, number of layers and learning constant.

Step:3 Training, Verification and use

1. Training of the neural network on the data set aside for training

2. Verification of the trained network, test data

3. Analysis of ANN result and possible modification of network

4. final integration of the train network into some application software if necessary before ANN is applied to model a particular problem fundamental aspects of the problem if self are to be studied to judge of the effectiveness of the technique weather closed loop pulsating heat pipe are suitable for be modeled by ANN can be ascertained by the following.

- Network accept a number of inputs which were fixed and it require a define input space.

- The results of the artificial neural network is depends on the training data so the training data should be more.

- A problem should be difficult and nonlinear so that no simple solution exist using the conventional

Technology.

- It should have well defined quantifiable goal a performance.

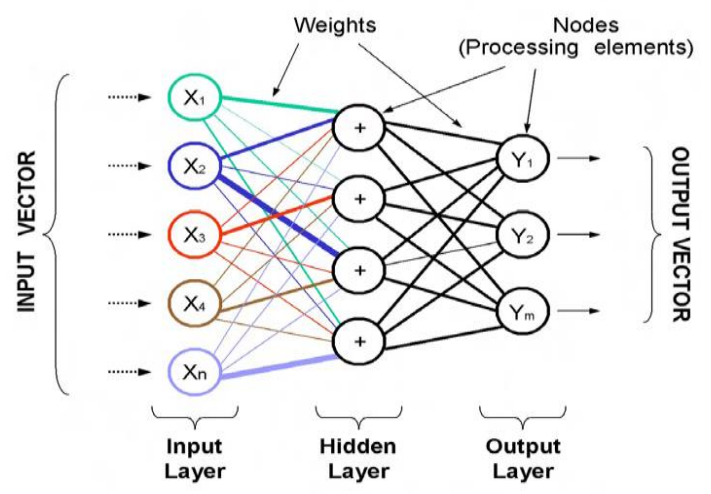

Figure 3.2 Neural network systems

\section{ANN RESULTS:}

\subsection{Water:}

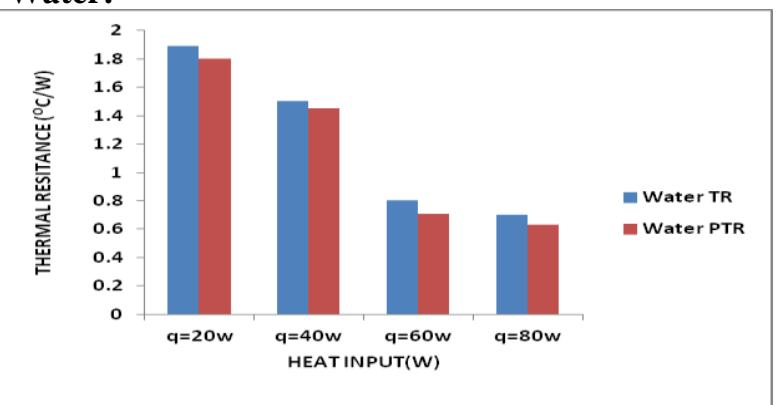

Graph 3.1 Comparison the experimental thermal resistance (TR) to predicted thermal Resistance (PTR)

Published By:

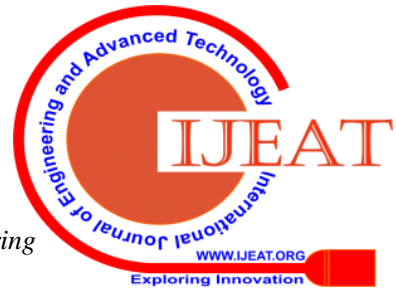


From the above graph 3.1.,the thermal resistance from experimental data is compared with the Matlab software data, Which is very accurate to experimental data.

\subsection{Ethanol:}

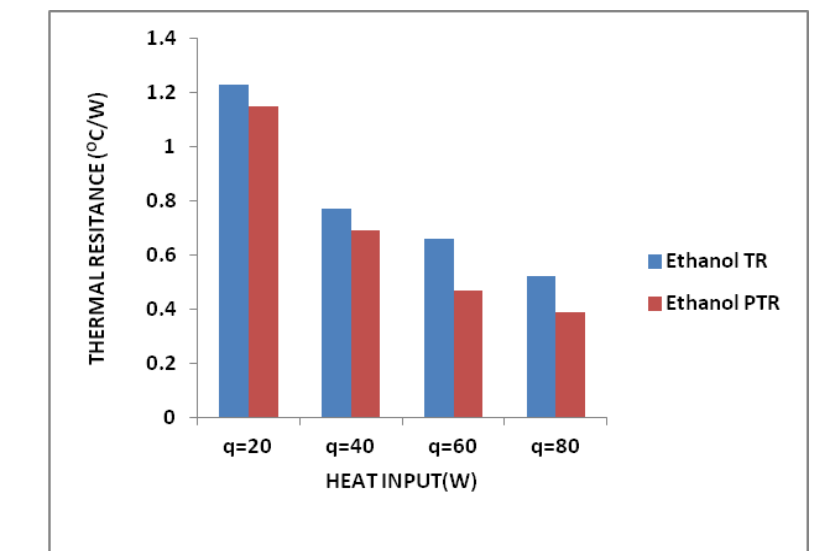

Graph 3.2 Comparison the experimental thermal resistance (TR) to predicted thermal Resistance (PTR)

From the above graph 3.2.,the thermal resistance from experimental data is compared with the Matlab software data, Which is very accurate to experimental data.

\section{CONCLUSIONS}

In this present study the performance of five turns pulsating heat pipe is investigated with both experimental and analysis is done with using ANN software with various working fluids like water,ethanol with various parameters like angle orientation and different heat inputs and calculated the thermal performance of pulsating heat pipe.

Inference from the experimental and artifical neural networks results of CLPHP:

As the heat input rises the thermal resistances are decreases smoothly in all working fluids.In comparison, ethanol working fluid PHP is shown better thermal performance than water.

At low heat input up to 20W, the thermal resistance increases rapidly and the PHP performance is more sensitive to the inclination angle whereas high heat input i.e. above $60 \mathrm{~W}$, the thermal resistance decreases smoothly and less independent to the inclination angle.

The thermal performance is considerably improved from vertical to inclined position.From present study, we can say that ethanol PHP has given the better thermal performance when it is operated at $45^{0}$ inclination.

The thermal resistance predicted by the Artificial neural network was very close to the thermal resistance which is obtained from experimental data.

\section{REFERENCES}

1. Ri-Guang Chi, Won-Sik Chung and Seok-Ho RhiThermal Characteristics of an Oscillating Heat Pipe Cooling System for Electric Vehicle Li-Ion Batteries (2018), Energies 2018, 11, 655

2. J Venkata Suresh, P Bhramara, CFD Analysis of Copper Closed Loop Pulsating Heat Pipe 5 (2018)5487-5495

3. Dong Soo Jang, Hyun Joon Chung, Yongseok Jeon, Yongchan Kim Thermal performance characteristics of a pulsating heat pipe at various nonuniform heating conditions 2018, International Journal of Heat and Mass Transfer 126 (2018) 855-863
4. M. Ebrahimi Dehshali, M.A. Nazari, M.B. Shafii* Thermal performance of rotating closed-loop pulsating heat pipes: Experimental investigation and semi-empirical correlation 2017, International Journal of Thermal Sciences 123 (2018) 14e26

5. Byeongchan Kim, Longnan Li, Jihoon Kim, Daejoong Kim A study on Thermal Performance of single ,Parallel Connected Pulsating Heat Pipe 2017, S1359-4311(17)33716-X

6. H R Deng, Y M Liu, R F Ma, D Y Han, Z H Gan and J M Pfotenhauer Experimental investigation on a pulsating heat pipe with hydrogen 2016, IOP Conf. Series: Materials Science and Engineering 101 (2015) 012065

7. Vipul M patel Hemanthkumar B.Mehta Artifical neural network modelling of closed loop pulsating heat pipe, World Academy of Science, Engineering and Technology

8. International Journal of Mechanical and Mechatronics Engineering Vol:10, No:10, 2016

9. Hemant B. Mehta1, Manish P. Pujara2, Jyotirmay Banerjee3 Prediction of Two Phase Flow Pattern using Artificial Neural Network 2013, International Conference on Chemical and Environmental Engineering (ICCEE'2013) April 15-16, 2013 Johannesburg (South Africa)

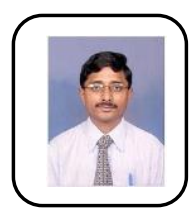

\section{AUTHORS PROFILE}

Mr. J. Venkata Suresh, Assistant Professor of Department of Mechanical Engineering, GRIET, completed his M. Tech with Energy Systems Specialization from JNTU College of Engineering Hyderabad. B.Tech in Mechanical engineering from V R Siddhartha Engineering College, affiliated to ANU Guntur.

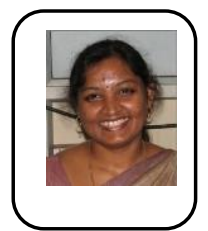

Dr P.Bhramara, Professor of Department of Mechanical Engineering, JNTUCEH completed her $\mathrm{PhD}$ from JNTU Hyderabad. She holds Master Degree in Refrigeration and Air Conditioning. She was graduated B.Tech from JNTU College of Engineering.

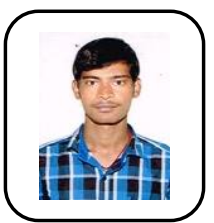

Mr. S. Sai Krishna completed his B.Tech Mechanical Engineering from DVR College of Engineering and Technology, Hyderabad. and Currently he is pursuing his M.Tech Thermal Engineering from Gokaraju Rangaraju Institute of Engineering and Technology, Hyderabad. 